\section{BLICKDIAGNOSE}

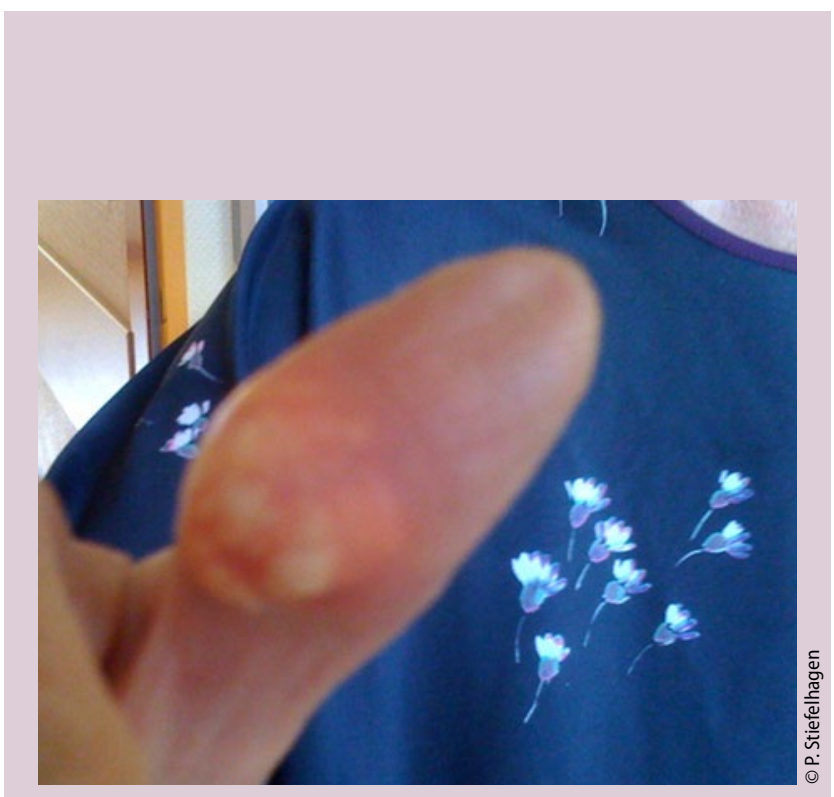

Weißlich-gelbliche Verhärtungen am Daumen.

\section{Handbefund I}

\section{Schmerzfreie neue Knubbel am Daumen}

Bei einer 65-jährigen Patientin war seit vielen Jahren ein metabolisches Syndrom mit Adipositas, Typ-2-Diabetes, Hyperlipoproteinämie und arterieller Hypertonie bekannt. Des Weiteren bestand eine chronische Niereninsuffizienz mit einer glomerulären Filtrationsrate (GFR) von $35 \mathrm{ml} / \mathrm{min}$. An der Innenseite des linken Daumens fanden sich nun umschriebene, weißlich-gelbliche Verhärtungen, die nicht schmerzhaft waren.

\section{Wie lautet die Diagnose?}
A) Tophi bei chronischer Gicht
B) Fremdkörpergranulom
C) Fingergelenksarthrose
D) Xanthelasma bei Hypertriglyzeridämie

Auflösung auf Seite 90.
Stellen Sie uns

Ihren Fall vor.

Bei Veröffentlichung erhalten Sie 100 Euro!

cornelius.heyer@ springer.com

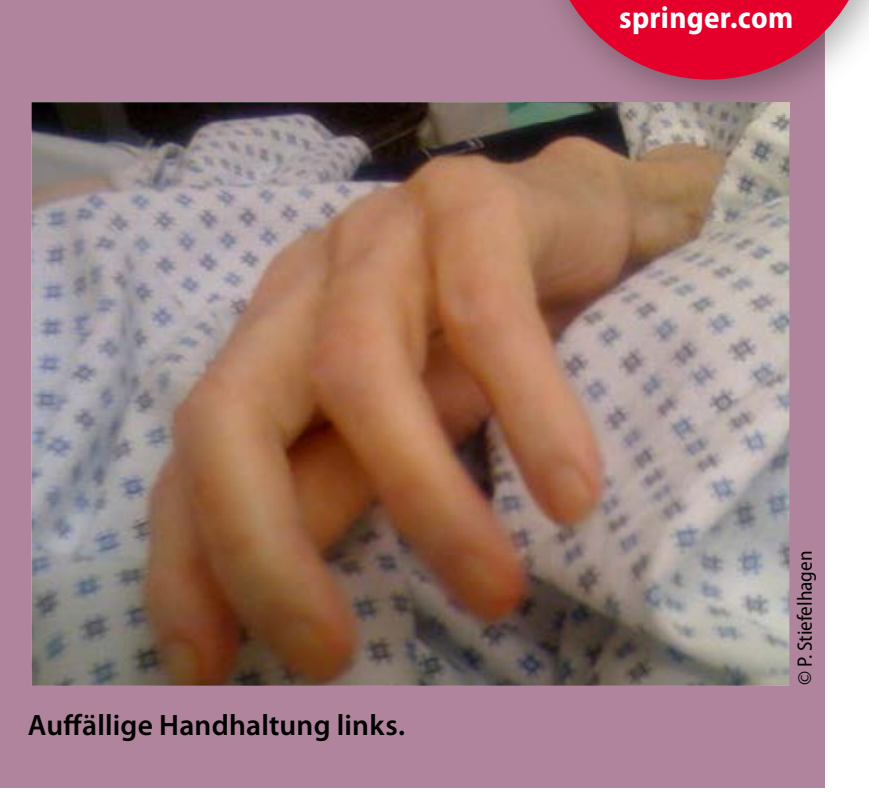

Handbefund II

\title{
Die linke Hand wirkt völlig verkrampft
}

Eine 84-jährige, pflegebedürftige Patientin mit einem demenziellen Syndrom wurde wegen zunehmender Verschlechterung des Allgemeinbefindens und Somnolenz bei Verdacht auf Exsikkose stationär eingewiesen. Bei der Aufnahme war die Patientin kreislaufstabil. Es bestand ein Zustand nach Strumektomie, ansonsten waren keine ernsthaften Vorerkrankungen bekannt. Auffallend war aber eine „Verkrampfung“ der linken Hand.

Wie lautet Ihre Diagnose?

A) Krallenhand bei Ulnaris-Parese

B) Spastische Lähmung bei ischämischem Insult

C) Pfötchenstellung bei hypokalzämischer Tetanie

D) Sklerodaktylie

Auflösung auf Seite 90.

\footnotetext{
$\rightarrow$ Dr. med. Peter Stiefelhagen

DRK-Krankenhaus, Alte Frankfurter Str. 12, D-57627 Hachenburg
}

\section{Weitere Fälle finden Sie online!}

Hier können Sie in unserer umfangreichen Sammlung stöbern und Ihren diagnostischen Riecher testen.

$\rightarrow$ www.springermedizin.de/blickdiagnose 